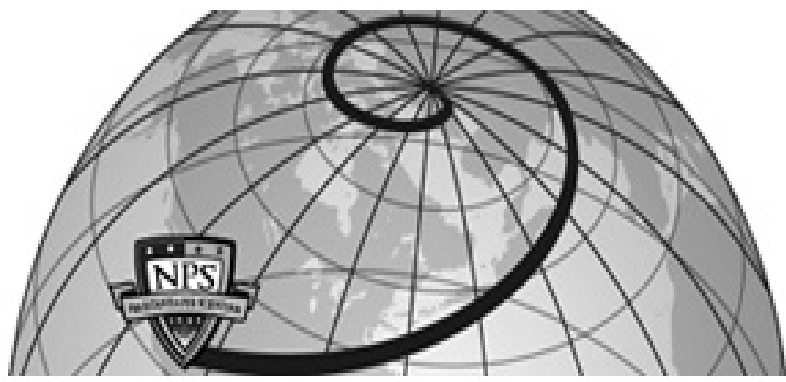

Calhoun: The NPS Institutional Archive DSpace Repository

\title{
Measuring transaction costs in DoD acquisition programs
}

Angelis, Diana; Dillard, John; Franck, Chip; Melese, Francois Monterey, California. Naval Postgraduate School

https://hdl.handle.net/10945/436

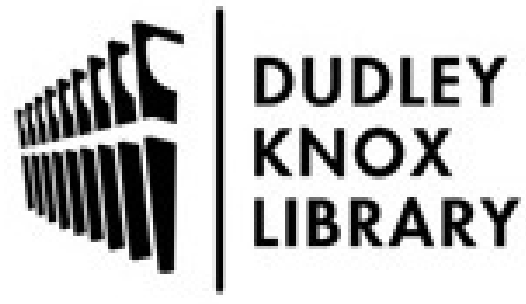

http://www.nps.edu/library
Calhoun is the Naval Postgraduate School's public access digital repository for research materials and institutional publications created by the NPS community. Calhoun is named for Professor of Mathematics Guy K. Calhoun, NPS's first appointed -- and published -- scholarly author.

Dudley Knox Library / Naval Postgraduate School 411 Dyer Road / 1 University Circle Monterey, California USA 93943 
NPS-AM-08-126

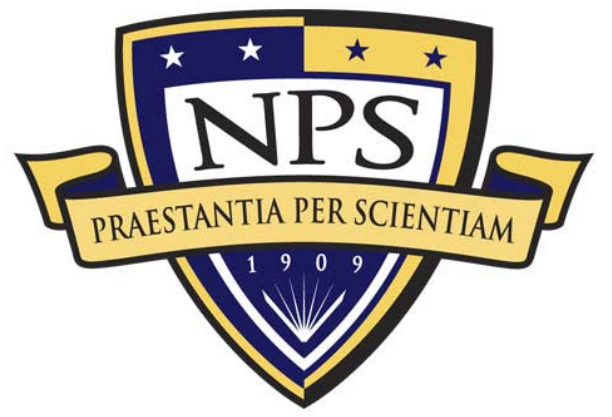

\section{ACQUISITION RESEARCH \\ SPONSORED REPORT SERIES}

Measuring Transaction Costs in DoD Acquisition Programs

29 September 2008

by

Dr. Diana Angelis, Associate Professor

John Dillard, Senior Lecturer

Brig Gen Chip Franck (ret.), Senior Lecturer

Dr. Francois Melese, Associate Professor

Naval Postgraduate School

Approved for public release, distribution is unlimited.

Prepared for: Naval Postgraduate School, Monterey, California 93943 
The research presented in this report was supported by the Acquisition Chair of the Graduate School of Business \& Public Policy at the Naval Postgraduate School.

To request Defense Acquisition Research or to become a research sponsor, please contact:

NPS Acquisition Research Program

Attn: James B. Greene, RADM, USN, (Ret)

Acquisition Chair

Graduate School of Business and Public Policy

Naval Postgraduate School

555 Dyer Road, Room 332

Monterey, CA 93943-5103

Tel: (831) 656-2092

Fax: (831) 656-2253

e-mail: ibgreene@nps.edu

Copies of the Acquisition Sponsored Research Reports may be printed from our website www.acquisitionresearch.org 


\section{Abstract}

This paper reports the preliminary results of a study to explore the influence of transaction costs on Department of Defense (DoD) cost estimates. It is an extension of previous work that established that Transaction Cost Economics has promising explanatory power in terms of costs of major DoD acquisition programs. The current work explores methods of measuring transaction costs as a first step in improving estimation methods by including explanatory variables that capture the coordination and motivation problems associated with a program. The preliminary results indicate that it is possible to measure contractor Systems Engineering/Program Management (SEPM) costs as a proxy for transaction costs. The ratio of SEPM to total costs was examined for two case studies (Javelin and ATACMS) for which ex-ante indicators of transaction costs had been assessed. The results are consistent in that the program with ex-ante indicators that indicated higher transaction costs also had a significantly higher SEPM ratio. Further research is required to better establish the relationship between transaction costs indicators and the quality of DoD cost estimates.

Keywords: Department of Defense (DoD) cost estimates, Transaction Cost Economics, Systems Engineering/Program Management (SEPM) costs 
THIS PAGE INTENTIONALLY LEFT BLANK 


\section{About the Authors}

Dr. Diana Angelis is an Associate Professor in the Defense Resources Management Institute at the Naval Postgraduate School in Monterey, CA. She joined the faculty in 1996. She studied accounting at the University of Florida and received a BS in Business Administration in 1977 and a BS in Electrical Engineering in 1985. She received her PhD in Industrial and Systems Engineering from the University of Florida in 1996. Her research interests include the application of activity-based costing in government organizations, cost estimating, the valuation of R\&D through options theory, and business reforms in defense management. She was commissioned an officer in the United States Air Force in 1984 and served as a program engineer until 1989. She joined the USAF Reserves in 1990 and has worked in both acquisition and test \& valuation with the Air Force Materiel Command. Dr. Angelis is a Certified Public Accountant and a Lieutenant Colonel in the US Air Force Reserve and is currently assigned to the Air Force Flight Test Center at Edwards AFB, CA.

Diana Angelis

Defense Research Management Institute

Naval Postgraduate School

Monterey, California 93943

Phone: 831-656-2051

E-mail: diangeli@nps.edu

John Dillard joined the Naval Postgraduate School faculty in the fall of 2000 with extensive experience in the field of systems acquisition management. His research focuses on defense acquisition policy changes and their implications. Dillard began his career in program and contract management after attaining a MS in Systems Management from the University of Southern California in 1985. He has been involved with myriad technologies and system concepts that have evolved into fielded products, such as the M-4 Carbine, 120mm Mortar, and M-24 Sniper Weapon. He was the Assistant Project Manager for Development of both the Army Tactical Missile System and, later, the JAVELIN Antitank Weapon System at Redstone Arsenal, Alabama. All of these systems incorporate state-ofthe-art technologies, are in sustained production and fielding, and are now battle-proven. He was the Product Manager for the Joint Advanced Special Operations Radio System, and in 1998 was appointed to head Defense Department contract administration in the New York metropolitan area. Dillard has consulted for the governments of Mexico and the Czech Republic on achieving excellence in the public sector. As an adjunct professor for the University of California at Santa Cruz, he teaches courses in project management and leadership to Silicon Valley public- and private-industry professionals.

John Dillard

Senior Lecturer

Graduate School of Business \& Public Policy

Naval Postgraduate School

Monterey, CA 93943-5197

Phone: (831) 656-2650

E-mail: jtdillard@nps.edu 
Raymond (Chip) Franck, PhD, Senior Lecturer, Graduate School of Business \& Public Policy, Naval Postgraduate School, retired from the Air Force in 2000 in the grade of Brigadier General after 33 years commissioned service. He served in a number of operational tours as a bomber pilot; staff positions, including the Office of Secretary of Defense and Headquarters, Strategic Air Command; and was Professor and Head, Department of Economics and Geography at the US Air Force Academy. His institutional responsibilities at NPS have included the interim chairmanship of the newly-formed Systems Engineering Department from July 2002 to September 2004, teaching a variety of economics courses, and serving on a number of committees to revise curricula for both the Management and Systems Engineering disciplines. His research agenda has focused on defense acquisition practices and military innovation.

Raymond (Chip) Franck

Senior Lecturer

Graduate School of Business \& Public Policy

Naval Postgraduate School

Monterey, CA 93943

Phone: (831) 656-3614

E-mail: refranck@nps.edu

Francois Melese, PhD, joined the Naval Postgraduate School faculty in 1987. He earned his undergraduate degree in Economics at UC Berkeley, his Master's at the University of British Columbia in Canada, and his PhD at the Catholic University of Louvain in Belgium. After five years as a faculty member in the Business School at Auburn University, Melese joined NPS as part of the Defense Resources Management Institute (DRMI). In his time at NPS, he has taught public budgeting and defense management in over two dozen countries and has published over 50 articles and book chapters on a wide variety of topics. More recently, at the request of the State Department and NATO Headquarters, he represented the US at NATO Defense meetings in Hungary, Ukraine, Germany and Armenia. His latest article (co-authored with Jim Blandin and Sean O'Keefe) appeared in the International Public Management Review. The article (available at www.ipmr.net) is entitled "A New Management Model for Government: Integrating ActivityBased Costing, the Balanced Scorecard and Total Quality Management with the spirit of the Planning, Programming and Budgeting System."

Francois Melese, $\mathrm{PhD}$

Associate Professor

Defense Resources Management Institute

School of International Graduate Studies

Naval Postgraduate School

Monterey, CA 93943

Tel: (831) 656-2009

E-mail: fmelese@nps.edu 
NPS-AM-08-126

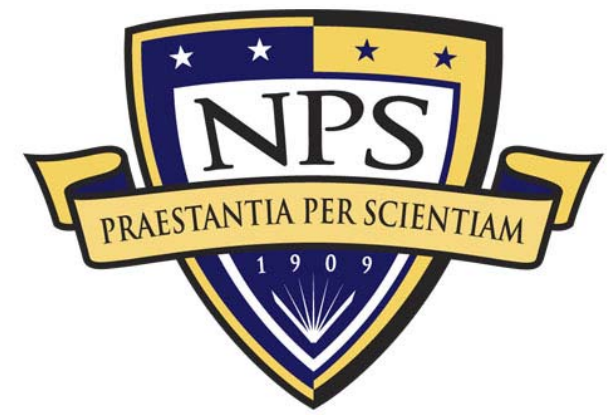

\section{ACQUISITION RESEARCH \\ SPONSORED REPORT SERIES}

\section{Measuring Transaction Costs in DoD Acquisition Programs}

29 September 2008

by

Dr. Diana Angelis, Associate Professor

John Dillard, Senior Lecturer

Brig Gen Chip Franck (ret.), Senior Lecturer

Dr. Francois Melese, Associate Professor

Naval Postgraduate School 
THIS PAGE INTENTIONALLY LEFT BLANK 


\section{Table of Contents}

Transaction Cost Economics................................................................ 1

TCE Issues in Defense Acquisition ...................................................... 3

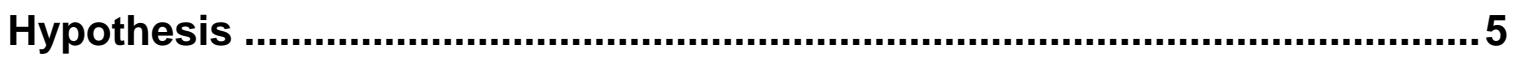

Measuring Transaction Costs in DoD Programs.......................................... 9

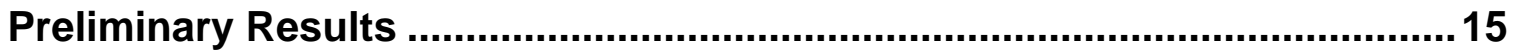

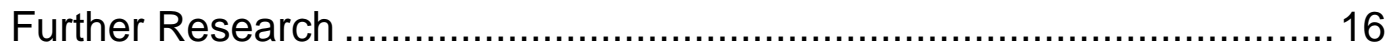

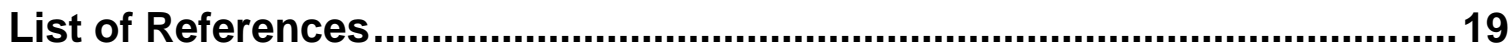


THIS PAGE INTENTIONALLY LEFT BLANK 


\section{Transaction Cost Economics}

Transaction cost economics (TCE) is a well-developed field of study that arises from the fundamental insight that markets are not frictionless and costless. A firm can be modeled as a network of contractual relationships (transactions) and one possible way to minimize transactions costs is the firm's internal bureaucracy. Coase (1937) was among the first to note that since market transactions are costly to manage, "by forming an [internal support] organization and allowing some authority to direct resources, certain costs are saved" (p. 392). However, vertical integration of transactions within the firm can have its own set of problems, such as

internal opportunistic behavior (lobbying for higher budgets), multi-tasking (based on measurements), and sub-optimization.

The nature of the transactions will determine the vertical boundaries of the firm and determine if a good or service is produced internally or externally. The firm will buy (outsource) if the internal costs are greater than the outsourced costs. A key insight from TCE is that firms should consider both the cost of production and the cost of transactions in evaluating "make-or-buy" decisions. The internal costs include the production costs and the internal bureaucracy ("agency") costs. The outsourced costs include the production costs and the transaction costs. TCE predicts that contracts and governance structures will be chosen so that transaction costs are reduced between buyer and seller. Conflicting objectives, however, can lead to opportunistic behavior including the challenge of relation-specific investments (or "asset specificity"), which can increase the risk to both parties in the transaction. Other key characteristics of transactions are complexity, uncertainty, length of the relationship, frequency, time sensitivity and operational significance. 
THIS PAGE INTENTIONALLY LEFT BLANK 


\section{TCE Issues in Defense Acquisition}

TCE provides a framework to facilitate understanding and improvement within defense acquisitions. When the Department of Defense (DoD) purchases a weapon system there are numerous transaction costs associated with source selection, periodic competition and renegotiation, contract negotiation and management, performance measuring and monitoring and dispute resolutions. The costs are not unique to DoD transactions. They are only magnified by the size of the transactions involved.

While outsourcing promises to lower production costs through competition and a reduction in internal "agency" costs, defense acquisitions rarely take place in a competitive market for a variety of reasons. Often, relation-specific investments necessary to produce large or complex weapon systems create barriers to competition. In addition, the acquisition process itself may limit competition by eliminating sellers: what starts as a competitive bid, can lead to a bilateral monopoly. Although some gains from competition may be captured up-front in the competitive bidding process, some of those gains are often recouped in latter stages by the expost monopoly provider.

Previous research has established that Transaction Cost Economics has promising explanatory power in developing costs estimates for major DoD acquisition projects (Melese, Franck, Angelis, \& Dillard, 2007). Coordination and motivation problems in commercial and contractual arrangements (such as acquiring major weapon systems) manifest themselves in some key indicators about the nature of the contractual relationship. They are also in evidence during observable events through the life of the projects-in matters relating to cost and schedule, as well as governance of the relationship.

Coordination Costs include: 
a) Search and Information Costs - to identify options and acquire timely, accurate and relevant information to evaluate alternatives;

b) Bargaining and Decision Costs-to choose an alternative and negotiate and write a contract; and

c) Policing and Enforcement Costs-to make payments and measure, monitor, and evaluate performance.

Motivation Costs include:

a) Costs to promote productive effort and incentives to encourage investment (better, faster, cheaper) and

b) Costs to deter unproductive bargaining and opportunistic behavior (renegotiation).

Factoring TCE cost considerations into cost-estimating efforts could help the DoD anticipate cost increases in four key areas that the GAO (1997) suggests will help explain cost overruns:

a) Constantly changing missions (uncertain demand/quantity/characteristics, bilateral monopoly, asset specificity, holdup, incomplete contracting);

b) Yearly incremental funding vs. multi-year appropriations (uncertainty, frequency, asset specificity, holdup);

c) Incentive problems (incomplete contracting, asset specificity, holdup); and

d) Insufficient oversight (measurement, monitoring costs). 


\section{Hypothesis}

Total costs are a function of production costs and transaction costs. In acquisition, production costs are developed from a Work Breakdown Structure (WBS): a production function mechanism that identifies the inputs and activities required to produce a specific weapon system. While the WBS provides an excellent accounting system to develop production cost estimates, it is inputoriented, not relationship-oriented. It therefore largely overlooks transaction costs (including coordination and motivation costs). In turn, this contributes to overly optimistic cost estimates. (Melese et al., 2007)

TCE theory suggests that coordination and motivation problems can lead to predictably higher costs when the program is completed. Thus, we hypothesize that higher program costs are predictable from both the indicators available prior to project start and during the course of the project itself-especially the choice of governance mechanisms. We also hypothesize that higher program costs observed during and after the acquisition project are ex-post indicators of hidden or unanticipated transaction costs. The basic model for TCE variables being a component of costs is summarized in Figure 1 below. 


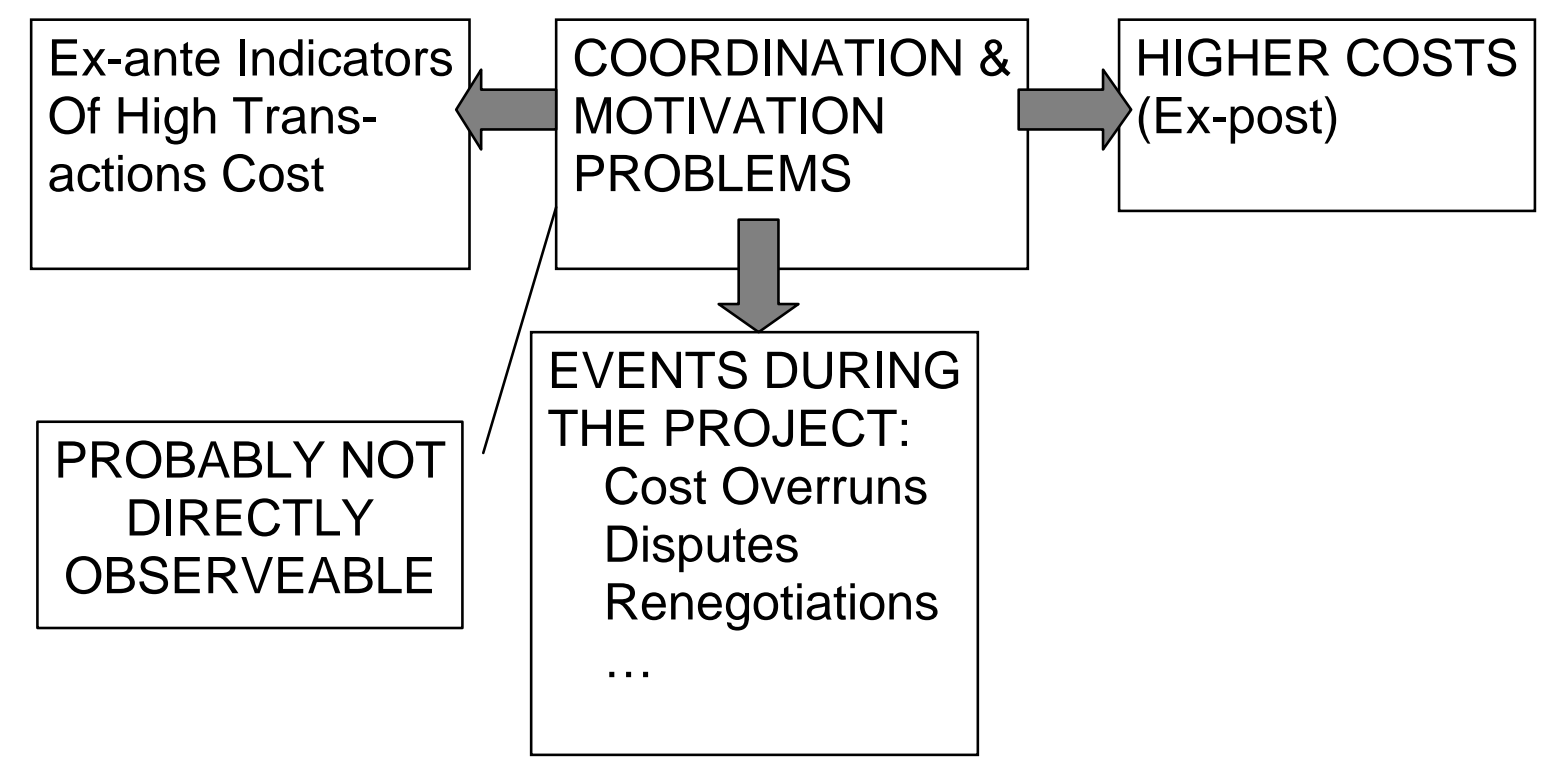

Figure 1. TEC Issues in Acquisition Projects and Hypothesized Cost Manifestations

Our basic hypothesis is that including TCE considerations (currently an omitted Variable in most calculations) can improve cost-estimation methodology by (a) helping to explain the systematic bias observed in initial cost estimates (Arena, 2006) and (b) increasing the general explanatory power of cost estimations. That is, we observe that the traditional WBS approach may overlook some important variables, resulting in initial cost estimates that are (a) not accurate and (b) downward biased. More specifically, the TCE perspective suggests the traditional WBS approach indeed overlooks two important variables: Coordination Costs and Motivation Costs. Unlike the production function approach of WBS, the TCE approach focuses on these and other key components of major weapon system acquisitions.

A key observation is that once production starts, the contractor acquires specialized information and assets. Production is often subject to economies of scale and learning curves that contribute to some natural monopoly power. The ability to shop around becomes restricted. Even though there may be contestability in the original design/development stage, bi-lateral monopoly arrangements emerge. 
The DoD system program office's functions/activities related to monitoring, controlling, information-gathering, reporting, decision reviews, enforcement, etc., tend to grow as oversight/governance increases with anticipated scale and risk of investments. Though program cost data may exist, it does not tell us the whole story on transaction costs.

Ideally, we would want to uncover the total program costs and subtract the cost of the contract. The difference consists of transaction costs (whose main components are coordination and motivation costs). This approach would capture the usual coordination costs and also any extra-normal costs that can arise as a result of hold-up and other motivation cost issues related to incomplete contracts and imperfect choice of governance mechanisms. 
THIS PAGE INTENTIONALLY LEFT BLANK 


\section{Measuring Transaction Costs in DoD Programs}

Based on the indicators shown in Figure 1, our research methodology unfolds in two parts: i) for Indicators of High Transactions Costs, we apply the Powell (2002) stoplight scheme (augmented by Frank, 2004), with special emphasis on asset specificity, ii) for observable manifestations of cost problems and governance issues during the program, we can consult histories of actual programs.

The "stoplight" method provides an ex-ante assessment of a program by examining the following characteristics:

1) Asset Specificity

GREEN: Many available suppliers

RED: One qualified supplier

2) Complexity

GREEN: Routine task or standard product

RED: Large scale, specialized skills

3) Length of Relationship

GREEN: Series of separate transactions

RED: Long-term, hard to foresee problems

4) Time Sensitivity

GREEN: Non-timely performance causes inconvenience

RED: Timely, short-fused performance highly important

5) Operational Significance 
GREEN: Unsatisfactory performance causes inconvenience

RED: Unsatisfactory performance degrades readiness or safety

In our previous research, we applied the stoplight scheme to two different acquisition projects: The Advanced Anti-Armor Weapon System-Medium (AAWSM), later to become the Javelin and the Army Tactical Missile System (ATACMS). The results are shown in Tables 1 and 2 .

\begin{tabular}{|l|l|}
\hline TCE Indicator & Assessment \\
\hline Asset Specificity & YELLOW \\
\hline Complexity & RED \\
\hline Length of Relationship & YELLOW \\
\hline Time Sensitivity & YELLOW \\
\hline Operational Significance & YELLOW \\
\hline
\end{tabular}

Table 1. Ex-ante Assessment of Javelin Development Program

\begin{tabular}{|l|l|}
\hline TCE Indicator & Assessment \\
\hline Asset Specificity & RED \\
\hline Complexity & GREEN \\
\hline Length of Relationship & GREEN \\
\hline Time Sensitivity & YELLOW \\
\hline Operational Significance & YELLOW \\
\hline
\end{tabular}

Table 2. Ex-ante Assessment of ATACMS Development Program 
For this study, we focused on ex-post indicators of transactions costs. More specifically, we examined how transaction costs might be captured in examining the outcomes of acquisition programs.

In order to test our hypothesis that the traditional WBS approach may overlook some important variables resulting in unrealistically low initial cost estimates, we would have to compare cost estimates for systems that included significant transaction costs with those of systems that did not include significant transaction costs. The first problem, then, was to find a way to measure transaction costs in acquisition programs. We initially proposed using the government's Program Management Office (PMO) costs as a proxy measure of the amount of transaction costs present in an acquisition program.

We started by examining information from the Consolidated Acquisition Reporting System (CARS) to find evidence of transaction costs. The information is contained in the Defense Acquisition University (DAU) Business Information Laboratory (BIL) database managed by OUSD (AT\&L) Acquisition Resources and Analysis. It includes information on contract performance and program cost from a variety of reports, such as Selected Acquisition Reports (SAR) and Defense Acquisition Executive Summaries (DAES), as well as other reports. Unfortunately, these reports do not contain the level of detail necessary to identify transaction costs. Specifically, there was no information on the amount of resources estimated or used for the PMO.

Instead, we looked at the Budget Item Justification sheets in the OSD budget. While there is some information on PMO costs in these documents, it is reported inconsistently or not at all (depending on the program and year). We also noted that what is included in PMO costs is not a complete picture of the resources used, since military salaries are excluded and civilian salaries may or may not be included depending on how they are funded. More importantly, what is and is not included in the category varies over time, making the identification of transaction costs difficult on a case-by-case basis and nearly impossible on a large scale. 
A more significant problem we encountered is that the information reported in CARS does not necessarily track to the information reported for the same program in the OSD budget. This problem was confirmed by OUSD (AT\&L) Acquisition Resources and Analysis and is an issue they have been working on for several years.

Contributing to the difficulty of identifying program transaction costs is the fact that program managers only report information on a program's major contracts for RDT\&E, procurement, military construction, and acquisition-related operation and maintenance. According to the CARS Users' Guide, SAR Section 15 (Contract Information) only includes the six largest, currently active contracts (excludes subcontracts) that exceed $\$ 40$ million in then-year dollars. For a given reporting quarter, these are generally the same contracts reporting in Section 6 (Program Background Data) of the DAES. If a previously reported contract is over $90 \%$ complete, it will no longer be reported. So, tracking Budget at Completion (BAC) and Estimate at Completion (EAC) at the program level involves moving targets as the individual contracts are completed and drop out of the CARS. Also, the total amount shown for the program in the OSD budget may include other contracts not reported in CARS. These issues suggest that the cost data currently collected for major weapon systems is not well suited for developing a cost model that includes transaction cost variables.

Due to the difficulties noted above, instead of looking at the government program management office (buyer) costs, we decided to look at the contractor's program management (seller) costs as a proxy for transactions costs. This effort proved to be more successful although extremely time consuming. The source documents for contractor cost are the Cost Data Summary Reports (CDSRs) (DD form 1921). While there are inconsistencies in reporting program management costs from contract to contract and contractor to contractor, the category itself is reported for every contract, and because it is based on the WBS, the reporting category is consistent within a contract. Different contractors report program 
management costs in somewhat different ways. For example, some contractors separate program management into Integrated Logistics Support (ILS) and non-ILS. Some report System Engineering and Program Management as two separate categories, while others report them in one category-Systems Engineering/Program Management (SEPM). These inconsistencies make it difficult but not impossible to compare program management costs across programs.

For this study we used SEPM as the proxy for transactions costs. It is worth noting that Systems Engineering might be more indicative of complexity problems associated with transactions costs, while Program Management might be more indicative of the broader category of coordination costs. Unfortunately, it is not always possible to separate the data into these two categories.

A ratio of SEPM costs to total program cost (per the CDSRs) was calculated for each program. The hypothesis is that a higher ratio could be an ex-post indicator of higher transactions costs. To offer a preliminary test of this hypothesis, we developed two case studies (Javelin and ATACMS) ${ }^{1}$.

${ }^{1}$ Both cases studies are described in detail in Angelis, Dillard, Franck \& Melese (2007). 
THIS PAGE INTENTIONALLY LEFT BLANK 


\section{Preliminary Results}

Our initial effort focused on the SEPM costs associated with the two previously assessed cases: the Javelin and ATACMS. One of the authors was fortunate to have served as the Assistant Project Manager for Research \& Development for each of the programs and was thus well qualified to examine transaction cost indicators for the two programs. Based on the ex-ante indicators assessed with the stoplight method (shown in Tables 1 and 2) along with direct assessment by the authors, it was clear that the Javelin exhibited more characteristics associated with high transactions costs than ATACMS.

The research question was whether the ex-post indicator (the SEPM ratio) would be higher for the Javelin than ATACMS. Several ex-post indicators suggested transaction costs might be higher for the Javelin when compared to ATACMS. One was the number of CDSRs filed for each program that reflects "complexity," namely the number of contracts required to develop and procure the weapon system. There were 20 filed for Javelin and only 9 filed for ATACMS. This was not unexpected, as there were up to three separate sources for the initial Javelin development, while only one source was used for the ATACMS. Clearly, higher transaction costs could be expected for the Javelin.

Another ex-post indicator was the type of contracts used for the programs. The Javelin used mostly Cost Plus contracts, indicating that the parties anticipated more uncertainty (risk) in the transactions. The ATACMS on the other hand used mostly Firm Fixed Price contracts, typical for lower risk and better defined transactions.

As expected, the SEPM indicator for the Javelin was higher than for the ATACMS. The Javelin had an SEPM ratio of .1629 while the ATACMS ratio was .0858. This supports the hypothesis that programs with more complex, risky relationships (as evidenced by the ex-ante indicators) will have higher transaction 
costs as evidenced by the ex-post SEPM ratio indicator. What is not clear at this point is whether the SEPM ratio reflects management's efforts to control those transaction costs or if they are merely caused by the riskier relationships.

\section{Further Research}

We have begun to look at SEPM ratio for a data set of major acquisition programs. We plan to see if there is a relationship between the SEPM ratio and the number of cost and schedule breaches experienced by a program as illustrated in Figures 2 and 3 . This would test the hypothesis that programs with riskier relationships have higher transactions costs and will experience more cost and schedule overruns. In turn, this could lead to ex-ante understanding of efforts needed to guide contractual types and other governance mechanisms to minimize transaction costs.

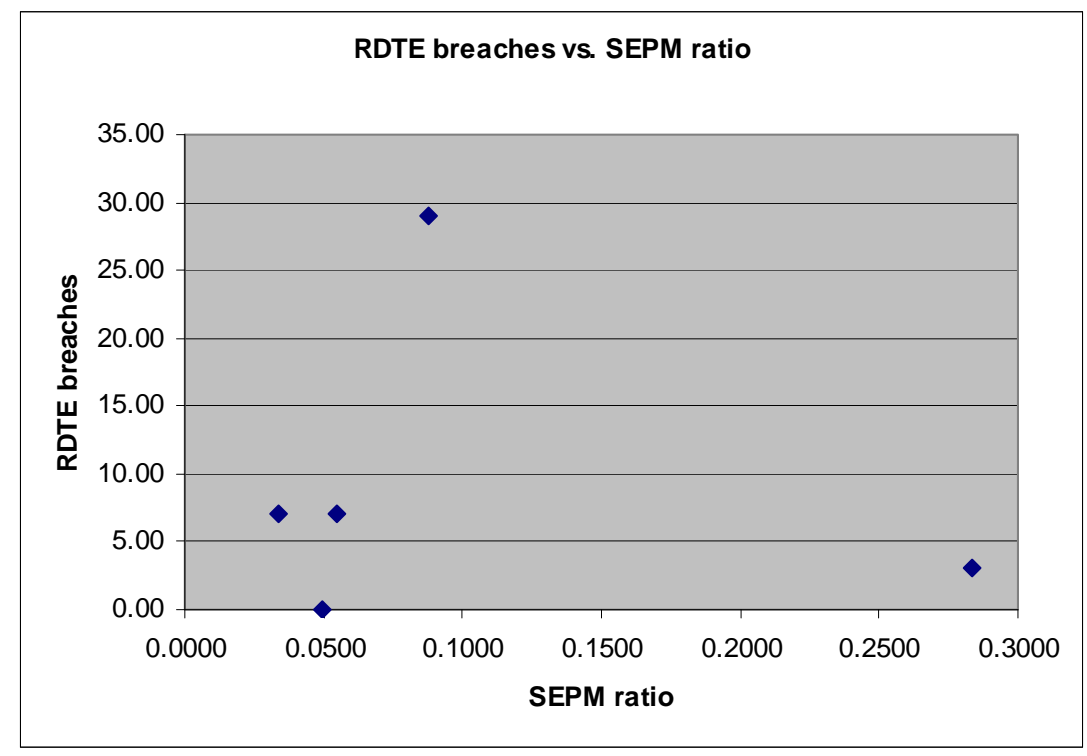

Figure 2. RDT\&E cost breaches vs. SEPM ratio 


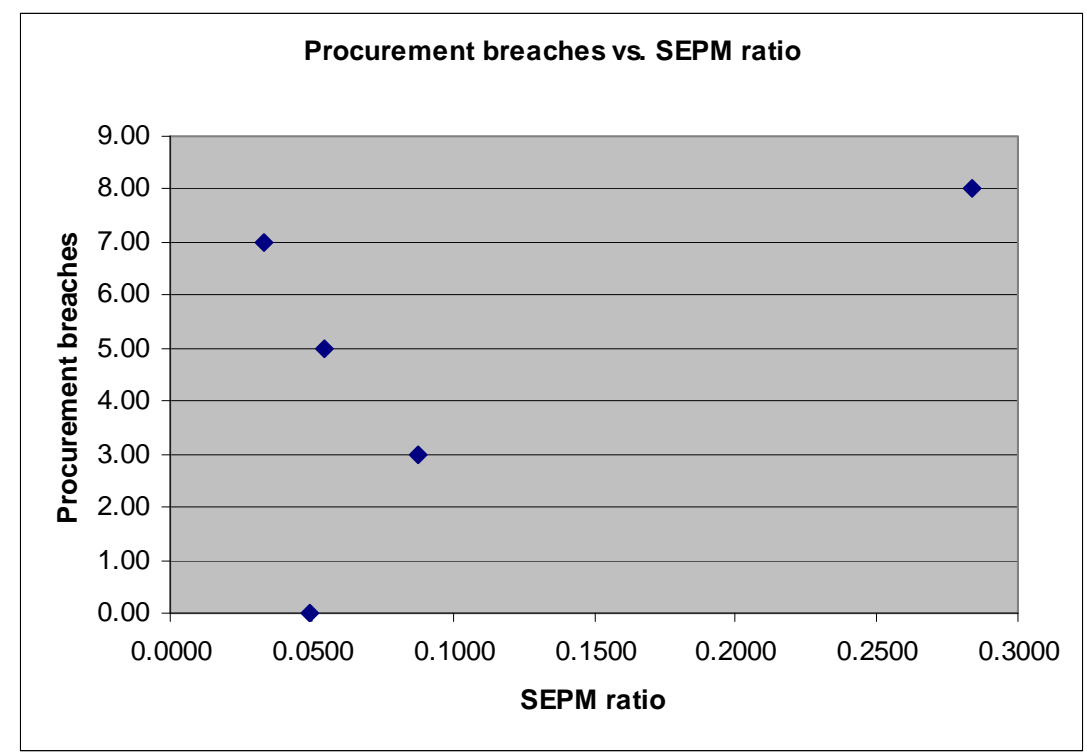

Figure 3. Procurement cost breaches vs. SEPM ratio

In the above graphs, cost breaches are defined as follows:

- $\quad$ RDT\&E Breach: When the program's research, development, test and evaluation costs exceed $15 \%$ of the baseline threshold.

- $\quad$ APUC Breach: When the average procurement unit cost exceeds the most recent APB threshold by $15 \%$. This is a congressionally reportable breach ${ }^{2}$.

We also plan to develop more case studies to examine ex-ante and ex-post indicators of transaction costs. To further explain the relationship between transaction costs and total acquisition costs, more standardized transaction cost indicators are needed. Specifically, information on cost avoidance measures, contract negotiation and adjudication, tapered integration and monitoring efforts should be examined and documented to facilitate research aimed at integrating transaction costs into DoD cost estimates.

${ }^{2}$ Since the law was enacted in 1982, Title 10 USC Section 2433, a "Nunn-McCurdy" unit cost breach occurs when a major defense acquisition program experiences an increase of at least $15 \%$ in program acquisition unit cost or average procurement unit cost above the unit costs in the acquisition program baseline. 
THIS PAGE INTENTIONALLY LEFT BLANK 


\section{List of References}

Angelis, D., Dillard, J., Franck, R., \& Melese, F.. (2007). Applying insights from transaction cost economics (TCE) to improve DoD cost estimation. In Proceedings of the Third Annual Acquisition Research Symposium, Monterey, CA: Naval Postgraduate School.

Arena, M.V., Leonard, R.S., Murray, S.E., \& Younossi, O. (2006). Historical cost growth of completed weapon systems. Santa Monica, CA: RAND.

Coase, R. (1937). The nature of the firm. Economica, 4, 386-405.

Dillard, J., Franck, R., \& Melese, F. (2006). A transaction cost economics approach to defense acquisition management. In Proceedings of the Third Annual Acquisition Research Symposium, Monterey, CA: Naval Postgraduate School.

DoD. Consolidated acquisition reporting system (CARS) user's guide. Update retrieved April 2007, from http://www.acq.osd.mil/cars/Downloads/CARS\%20Users\%20Guide.doc

DoD OUSD(C). Defense Budget Materials. Retrieved April 2007, from http://www.defenselink.mil/comptroller/budgetindex.html

Franck, R. (2004). Business case analysis and contractor vs. organic support (NPSAM-04-013). Monterey, CA: Naval Postgraduate School.

Franck, R., \& Melese, F. (2005). A transactions cost economics view of competitive sourcing. In Proceedings of Second Annual Acquisition Research Symposium, Monterey, CA: Naval Postgraduate School.

Government Accounting Office (GAO). (1997). Department of energy: Opportunities to improve management of major system acquisitions (GAO RCED 97-17). Washington, DC: Author.

Melese, F., Frank, F., Angelis, D., \& Dillard, J. (2007). Applying insights from transaction cost economics to improve cost estimates for public sector purchases: The case of US military acquisition. International Public Management Journal, 10(4), 357-385.

Powell, C.A. (2002). Transactions Cost Economics And A-76: A Framework For Defense Managers (Thesis). Monterey, Ca: Naval Postgraduate School. 
THIS PAGE INTENTIONALLY LEFT BLANK 


\section{3 - 2008 Sponsored Research Topics}

\section{Acquisition Management}

- $\quad$ Acquiring Combat Capability via Public-Private Partnerships (PPPs)

- BCA: Contractor vs. Organic Growth

- Defense Industry Consolidation

- $\quad$ EU-US Defense Industrial Relationships

- $\quad$ Knowledge Value Added (KVA) + Real Options (RO) Applied to Shipyard Planning Processes

- Managing Services Supply Chain

- MOSA Contracting Implications

- Portfolio Optimization via KVA + RO

- Private Military Sector

- Software Requirements for OA

- Spiral Development

- $\quad$ Strategy for Defense Acquisition Research

- The Software, Hardware Asset Reuse Enterprise (SHARE) repository

\section{Contract Management}

- Commodity Sourcing Strategies

- Contracting Government Procurement Functions

- Contractors in 21st Century Combat Zone

- Joint Contingency Contracting

- Model for Optimizing Contingency Contracting Planning and Execution

- $\quad$ Navy Contract Writing Guide

- Past Performance in Source Selection

- Strategic Contingency Contracting

- Transforming DoD Contract Closeout

- USAF Energy Savings Performance Contracts

- USAF IT Commodity Council

- $\quad$ USMC Contingency Contracting 


\section{Financial Management}

- Acquisitions via leasing: MPS case

- $\quad$ Budget Scoring

- $\quad$ Budgeting for Capabilities Based Planning

- Capital Budgeting for DoD

- $\quad$ Energy Saving Contracts/DoD Mobile Assets

- $\quad$ Financing DoD Budget via PPPs

- Lessons from Private Sector Capital Budgeting for DoD Acquisition Budgeting Reform

- $\quad$ PPPs and Government Financing

- ROI of Information Warfare Systems

- $\quad$ Special Termination Liability in MDAPs

- $\quad$ Strategic Sourcing

- Transaction Cost Economics (TCE) to Improve Cost Estimates

\section{Human Resources}

- Indefinite Reenlistment

- Individual Augmentation

- $\quad$ Learning Management Systems

- Moral Conduct Waivers and First-tem Attrition

- Retention

- The Navy's Selective Reenlistment Bonus (SRB) Management System

- Tuition Assistance

\section{Logistics Management}

- $\quad$ Analysis of LAV Depot Maintenance

- $\quad$ Army LOG MOD

- $\quad$ ASDS Product Support Analysis

- Cold-chain Logistics

- $\quad$ Contractors Supporting Military Operations

- Diffusion/Variability on Vendor Performance Evaluation

- Evolutionary Acquisition

- Lean Six Sigma to Reduce Costs and Improve Readiness 
- Naval Aviation Maintenance and Process Improvement (2)

- $\quad$ Optimizing CIWS Lifecycle Support (LCS)

- $\quad$ Outsourcing the Pearl Harbor MK-48 Intermediate Maintenance Activity

- $\quad$ Pallet Management System

- $\quad$ PBL (4)

- Privatization-NOSL/NAWCI

- RFID (6)

- Risk Analysis for Performance-based Logistics

- R-TOC Aegis Microwave Power Tubes

- Sense-and-Respond Logistics Network

- $\quad$ Strategic Sourcing

\section{Program Management}

- Building Collaborative Capacity

- Business Process Reengineering (BPR) for LCS Mission Module Acquisition

- $\quad$ Collaborative IT Tools Leveraging Competence

- Contractor vs. Organic Support

- Knowledge, Responsibilities and Decision Rights in MDAPs

- KVA Applied to Aegis and SSDS

- Managing the Service Supply Chain

- Measuring Uncertainty in Eared Value

- Organizational Modeling and Simulation

- Public-Private Partnership

- $\quad$ Terminating Your Own Program

- Utilizing Collaborative and Three-dimensional Imaging Technology

A complete listing and electronic copies of published research are available on our website: www.acquisitionresearch.org 
THIS PAGE INTENTIONALLY LEFT BLANK 


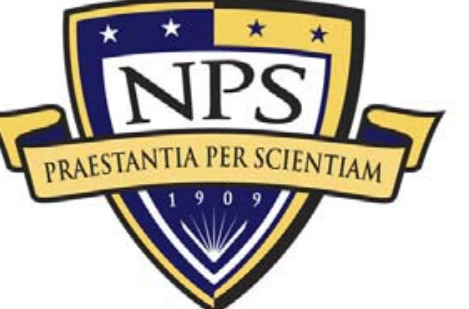

ACQUISITION RESEARCH PROGRAM GRADUATE SCHOOL OF BUSINESS \& PUBLIC POLICY NAVAL POSTGRADUATE SCHOOL 555 DYER ROAD, INGERSOLL HALL MONTEREY, CALIFORNIA 93943

www.acquisitionresearch.org 